\title{
Behavior Maintained by Intravenous Injection of Codeine, Cocaine, and Etorphine in the Rhesus Macaque and the Pigtail Macaque
}

\author{
Alice M. Young and James H. Woods \\ Department of Pharmacology, University of Michigan, Ann Arbor, Michigan 48109, USA
}

\begin{abstract}
Lever-pressing behavior of two species of macaque, the rhesus macaque ( $M$. mulatta) and the pigtail macaque ( $M$. nemestrina) was maintained by intravenous injection of codeine, etorphine, or cocaine. Monkeys responded under a fixed-ratio 30 timeout $600 \mathrm{~s}$ schedule of drug injection during two daily experimental sessions. Drug-maintained behavior was studied under two access conditions. Under the first condition, selected doses of codeine or cocaine were available for ten consecutive sessions. Under the second condition, responding was maintained by $0.32 \mathrm{mg} / \mathrm{kg}$ codeine or $0.32 \mathrm{mg} / \mathrm{kg}$ cocaine, and saline and selected doses of codeine, etorphine, and cocaine were substituted during single experimental sessions. Performance varied with drug and injection dose, access condition, and macaque species. For all three drugs, response tate increased and then decreased as injection dose increased. Maximal rates were maintained by $0.10-0.32 \mathrm{mg} / \mathrm{kg}$ codeine, $0.0003-$ $0.001 \mathrm{mg} / \mathrm{kg}$ etorphine, and $0.10-0.32 \mathrm{mg} / \mathrm{kg}$ cocaine. A cocaine dose of $0.32 \mathrm{mg} / \mathrm{kg}$ maintained higher rates than any dose of codeine or etorphine, and maintained higher rates when available during consecutive sessions than when substituted for codeine for a single session. Codeine maintained similar rates under all access conditions. The pigtail macaques had short catheter lives, did not readily acquire codeinemaintained responding, and displayed lower rates of drug-maintained lever pressing than the rhesus macaques.
\end{abstract}

Key words: Drug self-administration - - Fixed-ratio schedule - Codeine - Cocaine - Etorphine Rhesus macaques - Pigtail macaques

Studies of drug self-administration behavior in nonhuman primates frequently use the rhesus macaque as the experimental subject. In recent years, however, the

Offprint requests to: A. M. Young government of India has forbidden export of the rhesus monkey to the United States (Wade 1978), prompting a search both for a new source of rhesus macaques and for a new species of macaque suitable for long term intravenous drug self-administration studies. We report here a study of the lever pressing behavior maintained by intravenous injection of codeine, cocaine, and etorphine in rhesus macaques and another species of macaque: $M$. nemestrina, the pigtail macaque.

Behavior maintained by intravenous drug injection is controlled by a number of experimental variables, including the type and dose of drug available, the schedule contingencies in effect, the subject species used, and the experimental and pharmacological history of the subject (e.g., Goldberg 1976; Johanson $1978 \mathrm{a}$; Woods 1978). In the present study, lever pressing by rhesus and pigtail macaques was maintained by injection of codeine or cocaine under a schedule which required 30 responses to produce an injection [fixed-ratio (FR) 30 schedule]. Each injection was followed by a 10-minute period during which responses were ineffective in producing an injection. The response rates and number of injections maintained by different drugs and doses were compared under two access conditions. Under a repeated access procedure, selected doses of codeine and cocaine were made available during several consecutive experimental sessions. Under a single session substitution procedure, lever pressing was maintained by $0.32 \mathrm{mg} / \mathrm{kg}$ codeine or $0.32 \mathrm{mg} / \mathrm{kg}$ cocaine, and saline and selected doses of codeine, etorphine, and cocaine were substituted for the maintenance drug during single experimental sessions. The rate of drug-maintained performance varied with the drug and injection dose, the access conditions, and the species of macaque.

\section{Materials and Methods}

Subjects. Male and female pigtail macaques ( $M$. nemestrifa ) weighing $3.8-4.7 \mathrm{~kg}$ at the beginning of the experiment and male rhesus 
macaques ( $M$. mulatta) weighing $4.3-6.3 \mathrm{~kg}$ at the beginning of the experiment served as subjects. Each monkey was fed $75 \mathrm{~g}$ of Purina Monkey Chow 45 min prior to each of two daily experimental sessions. Drinking water was available at all times. For the control of tuberculosis, each monkey received a daily sugar cube impregnated with $0.5 \mathrm{cc}$ of an $80 \mathrm{mg} / \mathrm{cc}$ isoniazid solution.

Each monkey was surgically prepared with an indwelling siliconized rubber catheter (Rodhelm Reiss, Inc., Belle Mead, NJ); inner diameter $0.08 \mathrm{~cm}$; outer diameter $0.24 \mathrm{~cm}$, under ketamine $(10 \mathrm{mg} / \mathrm{kg}$ IM) and pentobarbital (15 mg/kg IV) anesthesia. The catheter was placed in a jugular, femoral, or brachial vein; veins were used successively as needed. The proximal end of the catheter terminated above the right atrium; the distal end passed subcutaneously to a point midway between the scalpulae and exited the skin via a stab wound. Additional details of the surgical procedure for the rhesus macaques have been reported by Deneau et al. (1969). The procedure for preparation of the brachial and femoral veins of the pigtail macaques was similar to that used for the rhesus. For preparation of the jugular vein in the pigtail macaques, however, a midline incision was used to expose the jugular vein in order to avoid the buccal sacs, which extend well below the clavicles.

In order to compare catheter life in $M$. mulatta and $M$. nemestrina, the life of each catheter implanted was determined for all pigtail macaques tested $(N=8)$ and for all rhesus macaques $(N=8)$ acquired and initially catheterized during the same time period (March to November, 1978) by the same personnel. The number of catheters implanted, their placement, and the total number of days each remained functional were determined over a 13.5 month period.

Apparatus. The monkeys were individually housed in open-faced fiberglass cubicles equipped with stimulus panels containing three 7 watt stimulus lamps and two response levers (Model PRL-001/12107, BRS/LVE, Beltsville, MD). A downward displacement of the lever requiring a 10 to $15 \mathrm{~g}$ force defined a response. The dimensions and construction of the cubicles are detailed in Woods (1980). Each monkey wore a stainless steel harness connected by a swivel to a jointed arm mounted to the back wall of the cubicle (Deneau et al. 1969). The catheter passed from the monkey through the jointed arm to a drug reservoir located behind the cubicle. Solutions were infused through the catheter at a rate of $1 \mathrm{cc}$ per $5 \mathrm{~s}$ by a roller infusion pump (Model MHRK 55, Watson and Marlow Co., Falmouth, England) Programming and data analysis were performed by a PDP $8 / 1$ computer (Digital Equipment Corp., Maynard, MA) located in an adjacent room. Cumulative recorders (Ralph Gerbrands Co., Arlington, MA) and a closed circuit TV recording system were available to record the behaviors of the subjects.

Procedure. After postoperative recovery, each monkey was shaped to press the right response lever when the right stimulus lamp was illuminated in order to produce a $5 \mathrm{~s}$ injection of $0.32 \mathrm{mg} / \mathrm{kg} /$ injection codeine. Initially, codeine infusions were available under a fixed ratio 1 (FR 1) schedule of reinforcement: each press of the right lever produced an infusion, during which the right stimulus lamp was extinguished, the middle stimulus light was illuminated green, and lever presses had no scheduled consequences. Left lever presses had no scheduled consequences at any time. Drug availability terminated after 130 min or 13 infusions, whichever occurred first. Experimental sessions were conducted twice per day; at least $4 \mathrm{~h}$ elapsed between successive daily sessions. When a monkey received all available infusions during two consecutive experimental sessions, a $10 \mathrm{~s}$ timeout (TO $10 \mathrm{~s}$ ) period, during which the right and middle stimulus lamps were extinguished and lever press responses had no programmed consequences, was introduced following each infusion. The number of responses required to produce an infusion (the FR value) and the duration of the TO period were systematically increased to FR 30 TO $600 \mathrm{~s}$ during successive experimental sessions according to the criteria reported by Woods (1980). If a monkey did not self-inject all available infusions and display regular rates of lever pressing under the FR 30 TO $600 \mathrm{~s}$ schedule, one or more of the following manipulations was performed: the $0.32 \mathrm{mg} / \mathrm{kg}$ codeine solution was replaced with a $0.1 \mathrm{mg} / \mathrm{kg}$ cocaine solution; the TO value was reduced to $10 \mathrm{~s}$ and gradually increased over successive sessions; or the FR value was decreased and then increased over successive sessions.

In order to compare the acquisition of drug-maintained performance by the two macaque species, the number of experimental sessions required to achieve the final schedule values for codeine injection was determined for all pigtail macaques initially exposed to codeine $(N=7)$ and for the eight rhesus macaques catheterized and exposed to the codeine self-injection schedule during the same time period. An eighth pigtail macaque was initially exposed to cocaine $(0.1 \mathrm{mg} / \mathrm{kg} /$ infusion) and shaped to lever press under the FR 30 TO $600 \mathrm{~s}$ schedule. After several weeks the infusion solution was changed to deliver $0.32 \mathrm{mg} / \mathrm{kg}$ codeine.

When performance under the FR 30 TO $600 \mathrm{~s}$ schedule was characterized by fairly high response rates during the FR component, delivery of all scheduled $0.32 \mathrm{mg} / \mathrm{kg}$ codeine injections, few responses on the inactive left lever, and few responses during infusions or TO components, saline tests were conducted. Saline $(0.9 \% \mathrm{NaCl})$ was substituted for codeine every fourth experimental session until the rate of lever pressing under the FR component fell below 0.2 responses/s or until six saline sessions had occurred. Codeine was available during all intervening sessions. When a subject displayed low response rates and received few infusions during saline availability sessions, novel drugs and doses were introduced under one or both of the following access conditions.

Under a repeated access procedure, five rhesus macaques $(100$, $805,1232,1238, \mathrm{D} 2)$ and five pigtail macaques $(1197,1198,1200$, $1201,1202)$ were exposed to selected doses of codeine $(0.03,0.10$, $0.32,1.0 \mathrm{mg} / \mathrm{kg} /$ infusion) or cocaine $(0.03,0.1,0.32,1.0 \mathrm{mg} / \mathrm{kg} /$ infusion). Each dose was studied for ten consecutive experimental sessions or until response rates fell below 0.02 responses per $\mathrm{s}$ for three consecutive sessions. All codeine doses were studied before cocaine was tested in all subjects except pigtail macaque 1197. Doses of each drug were presented in an unsystematic sequence.

Under a single session substitution procedure, the lever-pressing response of seven rhesus macaques $(712,713,753,787,876,890$, E3) and four pigtail macaques $(1197,1198,1201,1202)$ was maintained under the FR 30 TO $600 \mathrm{~s}$ schedule by $0.32 \mathrm{mg} / \mathrm{kg}$ codeine or $0.32 \mathrm{mg} / \mathrm{kg}$ cocaine infusions. During selected afternoon sessions, a novel drug solution was substituted for the maintenance drug. Under the $0.32 \mathrm{mg} / \mathrm{kg}$ codeine maintenance schedule, substitution doses of codeine, cocaine, and etorphine were studied in both species of macaque. The data for codeine substitution testing in the rhesus macaque have been previously reported (Woods 1980); they are presented here to allow easy comparison of codeine - maintained performance by the rhesus and pigtail macaques. Under the $0.32 \mathrm{mg} / \mathrm{kg}$ cocaine maintenance schedule, substitution doses of cocaine and codeine were studied in the rhesus macaque, and codeine was studied in the pigtail macaque. In the rhesus macaques, selected doses of each test drug were made available to each of three subjects during two separate substitution sessions. In the pigtail macaques, one observation of selected doses of each drug was made in each of four subjects under codeine maintenance, and in each of two subjects under cocaine maintenance. All single session substitution tests were separated by at least three sessions of maintenance drug availability. One or more saline substitution tests were conducted between tests of different drugs for each monkey. Throughout the study, single session substitution tests were conducted only when inspection of the individual monkey's baseline performance revealed no systematic increases or decreases in lever pressing rate or number of injections received over successive maintenance drug sessions. The test range of doses for each drug was determined by the observed behavioral effects. The substitution dose of each drug was decreased until a dose was found that maintained response rates and total infusions no 
higher than those maintained by saline, and was increased until a dose was reached that maintained rates lower than those controlled by the next lower dose. Exception was made to this criterion if severe central nervous system depression or prodromal convulsive signs were observed during closed-circuit TV monitoring of a subject during a substitution test. In all such cases, the experimental session was terminated, and that dose was not tested further.

Data Analysis. FR response rate (the rate of right lever presses during the FR component divided by the seconds elapsed from onset of the FR component until solution delivery) and the number of infusions delivered were calculated for each experimental session. The rate of responding on the right lever during infusions and TO periods and the rate of responding on the left lever over the entire experimental session were also calculated.

Drugs. Codeine phosphate, cocaine hydrochloride, and etorphine hydrochloride were dissolved in $0.9 \% \mathrm{NaCl}$. All doses are expressed as $\mathrm{mg}$ of the salt per $\mathrm{kg}$ of body weight.

\section{Results}

Catheter Life. Catheter life was shorter for the pigtail than for the rhesus macaque. During the 13.5 month observation period, the median catheter life of the 20 catheters implanted in the pigtail macaques was 27 days (range 5-266 days), whereas the median life of the 22 catheters implanted in the rhesus macaques was 51 days (range 2-295 days). The difference between the two species was largely the result of the monkeys' pulling the catheters within 40 days of implantation. In the pigtail macaques, $60 \%$ of all catheters lasted fewer than 40 days, while in the rhesus macaques, only $23 \%$ failed within 40 days of implantation. No catheters were lost to infection within 40 days in either group of monkeys.

Drug Self-Injection: Acquisition. The rhesus macaques acquired codeine-maintained performance faster and displayed higher rates of lever pressing maintained by $0.32 \mathrm{mg} / \mathrm{kg}$ injections of codeine than did the pigtail macaques. Following initial catheterization, all rhesus macaques achieved the final FR 30 TO $600 \mathrm{~s}$ schedule contingencies, in a median of 42.5 sessions (range 23110). Stable performance was characterized by FR response rates of one to two responses per s, delivery of 12 to 13 injections per session, infrequent responses during the TO component or infusions, and very few responses on the left lever. In contrast, only four of the seven pigtail macaques initially exposed to codeine achieved the final schedule contingencies, and one of these displayed regular codeine self-injection only after exposure to $0.10 \mathrm{mg} / \mathrm{kg}$ cocaine injections for nine sessions. Only one of these pigtail macaques lost a catheter during the acquisition period. These four pigtail macaques required a median of 81.5 sessions (range 27-145) to achieve the final schedule value for $0.32 \mathrm{mg} / \mathrm{kg}$ codeine injection. Their stable performance was characterized by FR response rates of 0.3 to 1.0 responses per $\mathrm{s}$, delivery of 12 to 13 injections per session, infrequent left lever responses, and few responses during the TO component or infusions. The remaining three pigtail macaques failed to selfadminister all available codeine injections during a session or to respond at rates higher than 0.2 responses per s during the FR component; all three frequently lost their catheters and were removed from the experiment when their veins were exhausted. When saline replaced codeine as the infusion solution, monkeys of both species displayed low FR response rates and received few injections during the experimental session. FR responses rates during the final two saline substitution sessions averaged 0.06 responses per s (range $0.04-$ 0.11 ) for the rhesus macaques and 0.05 responses per $\mathrm{s}$ (range $0.02-0.10$ ) for the pigtail macaques. The number of injections averaged 6.8 (range $6-8.7$ ) and 5.7 (range $4.3-8.5$ ), respectively.

Drug Self-Injection: Codeine. Codeine-maintained FR response rates varied as a function of the injection dose and the subject species, but did not vary markedly across access conditions (Fig. 1). Under the repeated access procedure, as the codeine injection dose increased, FR response rates increased to a maximum and then decreased for both species of macaque (Fig. 1, left panel). The number of injections received during an experimental session also increased to the maximum possible and then decreased as the codeine injection dose increased. At 0.03 and $0.10 \mathrm{mg} / \mathrm{kg}$ codeine, both FR response rate and the number of injections received were lower for the pigtail macaques than for the rhesus. At 0.32 and $1.0 \mathrm{mg} / \mathrm{kg}$ codeine, the two species selfadministered the same number of injections per session and displayed considerable overlap of FR response rates, but average FR response rates of the pigtail macaques were consistently below those of the rhesus macaques. For both species, the response rates maintained by $0.32 \mathrm{mg} / \mathrm{kg}$ codeine increased during a second determination at this dose. All codeine doses tested maintained FR response rates higher than those maintained by saline during single session substitutions in both macaque species. Saline was studied under the repeated access procedure in one rhesus macaque and one pigtail macaque. FR response rates during the first saline session and the mean FR response rates over the final five saline sessions $(0.08$ and 0.10 responses per $\mathrm{s}$ for the rhesus macaque; 0.01 and 0.004 responses per $s$ for the pigtail macaque) were lower than the rates maintained by any dose of codeine under the repeated access procedure in either subject. The frequency of left lever responses and of right lever responses during the TO component or infusions did not change as a function of codeine injection dose. 


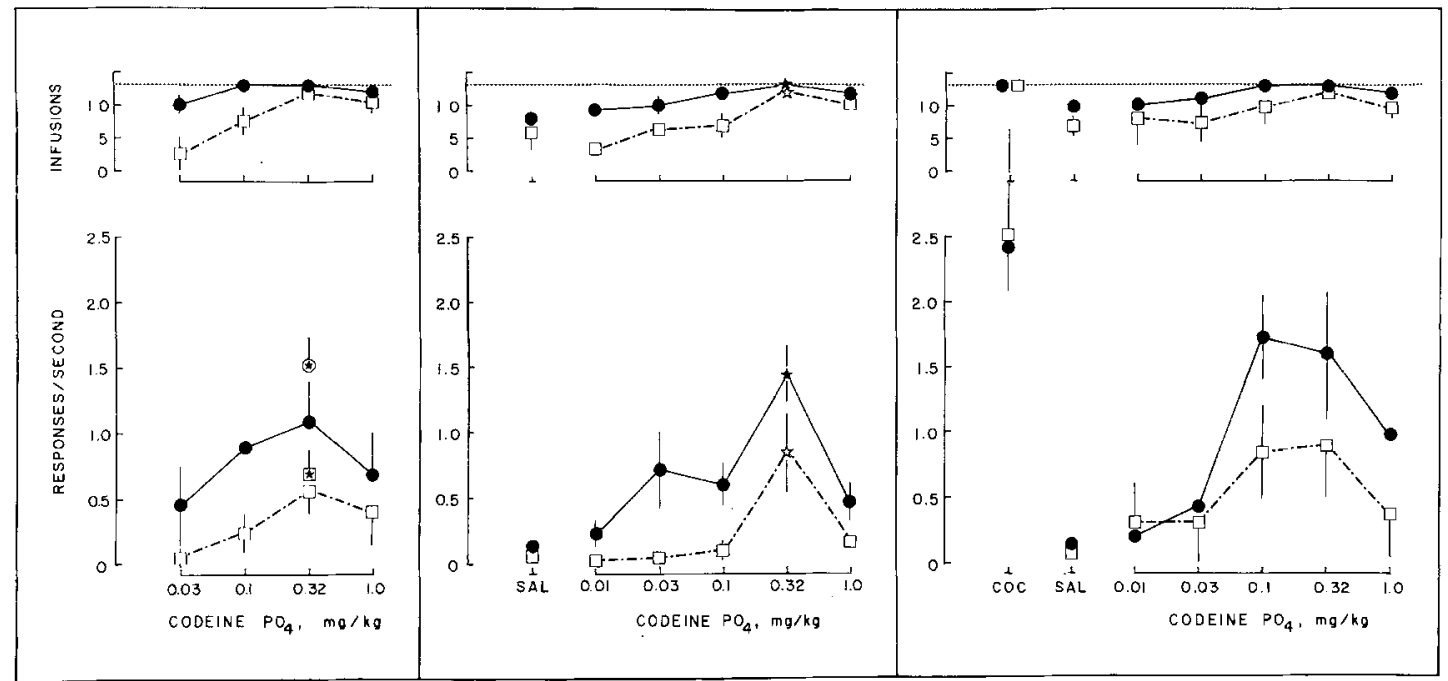

Fig. 1. Response rates and number of injections during the FR component of the FR 30 TO $600 \mathrm{~s}$ schedule of codeine injection as a function of codeine injection dose for two species of macaque. Closed circles and solid lines present data for rhesus macaques; open squares and dashed lines present data for pigtail macaques. The left panel presents data from the final five sessions at each codeine injection dose under the repeated access procedure; each point represents the mean \pm SEM of individual mean data for four subjects over the final five sessions. The starred symbols at $0.32 \mathrm{mg} / \mathrm{kg}$ codeine represent the second determination at this dose for both macaque species. The middle panel presents data from single substitution sessions in which different injection doses were substituted for a $0.32 \mathrm{mg} / \mathrm{kg}$ codeine (starred symbols) maintenance dose. The right panel presents data from single substitution sessions in which different codeine doses were substituted for a $0.32 \mathrm{mg} / \mathrm{kg}$ cocaine maintenance dose $(C O C)$. For the middle and right panels, each point represents the mean \pm SEM of the average FR response rate or number of injections during two single substitution sessions for each of three rhesus macaques and the mean \pm SEM of single determinations in each four (codeinemaintenance) or two (cocaine-maintenance) pigtail macaques. Data from saline substitution sessions are presented at $S A L$. The points at $0.32 \mathrm{mg} / \mathrm{kg}$ codeine (middle panel) and at COC (right panel) represent the mean \pm SEM of the average data for each subject from two random afternoon maintenance drug sessions during the period of substitution testing. Under all access conditions the maximum number of injections available per session, indicated by the dotted lines, was 13

Figure 2 shows cumulative records of lever-pressing performance in the FR component of the FR $30 \mathrm{TO}$ $600 \mathrm{~s}$ schedule by a representative rhesus macaque (1238) and pigtail macaque (1197) at the four codeine doses studied under the repeated access procedure. For both species, the pattern of lever pressing varied as a function of the injection dose available. For the rhesus macaque, $0.32 \mathrm{mg} / \mathrm{kg} /$ injection maintained high response rates throughout all FR components of a session. At lower injection doses, running rate remained high, but 1238 frequently paused at the beginning of the FR component or during a ratio run. At $1.0 \mathrm{mg} / \mathrm{kg}, 1238$ rapidly completed several ratios at the beginning of the session, then responded irregularly during later FR components. In general, the pigtail macaque displayed both longer prerun pauses and slower running rates than the rhesus macaque at all doses tested, resulting in lower overall FR response rates. At $0.32 \mathrm{mg} / \mathrm{kg}$, pigtail macaque 1197 showed a pause and run response pattern, with pause length increasing during a session. At the lower doses, this pigtail macaque frequently paused for extended periods before initiating FR responding. At $1.0 \mathrm{mg} / \mathrm{kg}, 1197$ completed several ratios at a fairly high rate, then paused at the beginning of each subsequent FR com- ponent before completing the ratio at a low rate. For both species, the response patterns at codeine doses higher or lower than $0.32 \mathrm{mg} / \mathrm{kg}$ decreased FR response rate and the number of injections delivered during an experimental session.

The tested range of codeine doses maintained similar FR response rates under the repeated access procedure and both the cocaine- and codeinemaintenance single session substitution procedures (Fig. 1). Under all access conditions, codeine maintained lower FR response rates in the pigtail macaques than in the rhesus macaques. When lower or higher codeine doses were substituted for the $0.32 \mathrm{mg} / \mathrm{kg}$ codeine maintenance dose for single sessions, FR response rates and the number of infusions received decreased (Fig. 1, middle panel). For the rhesus macaques, codeine doses of $0.03,0.1$ and $1.0 \mathrm{mg} / \mathrm{kg}$. maintained rates higher than those maintained by saline. For the pigtail macaques, however, no substitution dose of codeine maintained rates higher than those maintained by saline. Under the cocainemaintenance substitution procedure, $0.1-1.0 \mathrm{mg} / \mathrm{kg}$ codeine maintained $F R$ response rates higher than those maintained by saline for both species, with 0.1 and $0.32 \mathrm{mg} / \mathrm{kg}$ maintaining the highest rates (Fig. 1, 
Fig. 2

Representative cumulative records for a rhesus macaque (no. 1238) and a pigtail macaque (no. 1197) under the FR 30 TO 600 s schedule at various injection doses of codeine under the repeated access procedure. Ordinate: cumulative responses; abscissa: time. The recording pen reset to the baseline at the end of the experimental session. Short diagonal strokes indicate codeine injections; the recorder did not run during the $600 \mathrm{~s}$ timeout period following each injection

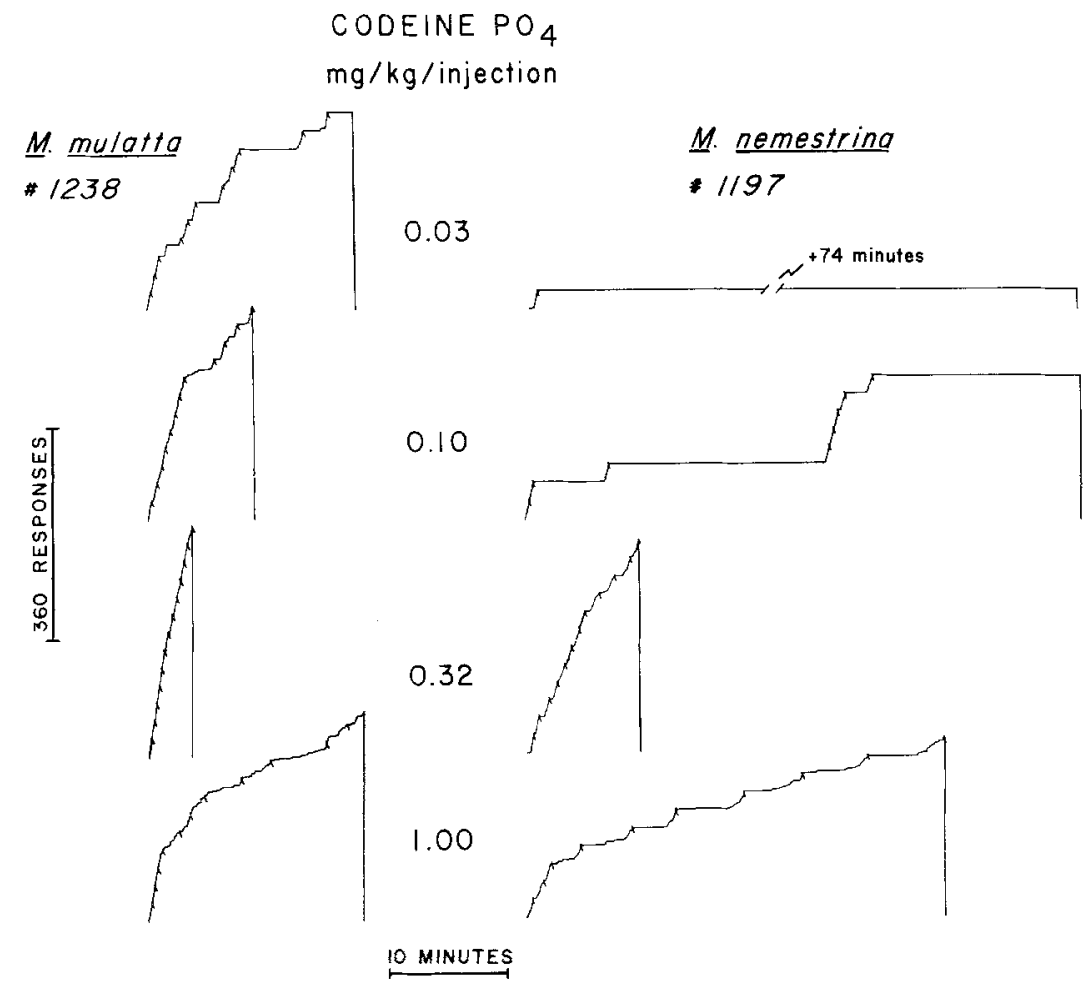

right panel). No substitution dose of codeine maintained rates as high as those maintained by the maintenance dose of $0.32 \mathrm{mg} / \mathrm{kg}$ cocaine. Again, the pigtail macaques displayed lower rates of codeine-maintained behavior than did the rhesus, even though the rates of cocaine-maintained performance were higher in the pigtail macaque than in the rhesus. Comparison of the FR response rates maintained by substitution doses of codeine under the repeated access procedure and the codeine- and cocaine-maintenance substitution procedures showed that, with one exception, each dose of codeine maintained similar rates under all three conditions within each species. One codeine dose, $0.10 \mathrm{mg} / \mathrm{kg}$, maintained higher rates in both species under the cocaine-maintenance substitution procedure than under either the codeine-maintenance substitution procedure or the repeated access procedure.

Drug Self-Injection: Etorphine. The differences in drugmaintained performance between the rhesus and pigtail macaques were not specific to codeine. The narcotic agonist etorphine also maintained lower FR response rates in the pigtail than in the rhesus macaques (Fig. 3). When substituted for codeine, etorphine maintained responding in a dose-dependent manner. For the rhesus macaques, an injection dose of $0.0003 \mathrm{mg} / \mathrm{kg}$ maintained the highest FR response rates, which averaged $73 \%$ of the rate maintained by the codeine maintenance dose. Higher and lower doses of etorphine maintained lower FR response rates, accompanied by a decreased

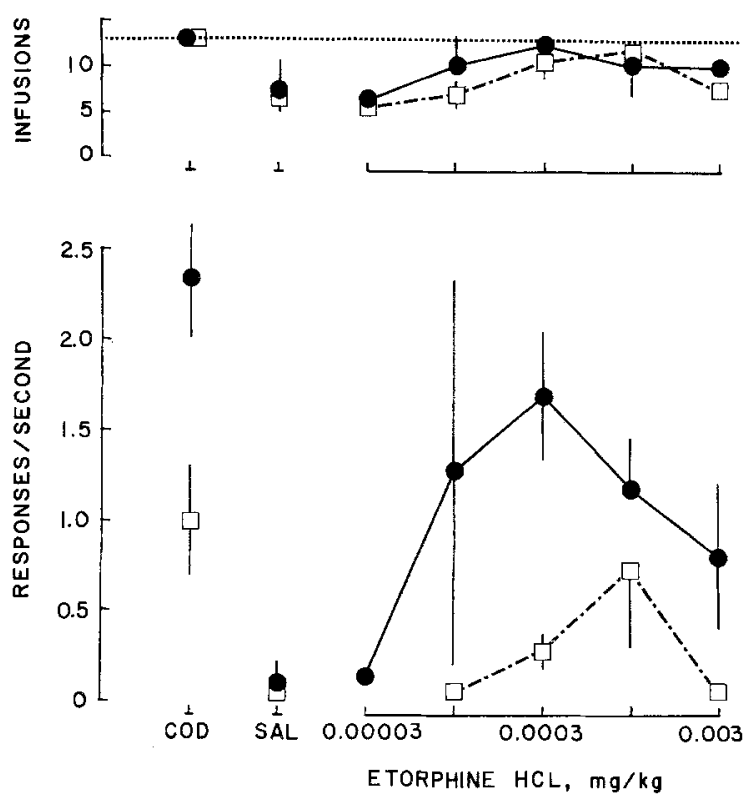

Fig. 3. Response rates and number of infusions during the $F R$ component of the FR 30 TO $600 \mathrm{~s}$ schedule when etorphine doses were substituted for $0.32 \mathrm{mg} / \mathrm{kg}$ codeine (COD) under the single session substitution procedure. Closed circles and solid lines present the mean \pm SEM of the average data during two single session substitutions for each of three rhesus macaques. Open squares and dashed lines present the mean \pm SEM for single substitution sessions in each of four pigtail macaques. Data from saline substitution sessions are presented at $S A L$. The points at COD represent the mean \pm SEM of the average data for each subject from two random afternoon $0.32 \mathrm{mg} / \mathrm{kg} /$ injection codeine sessions during the period of substitution testing. The maximum number of injections available per session, indicated by the dotted line, was 13 


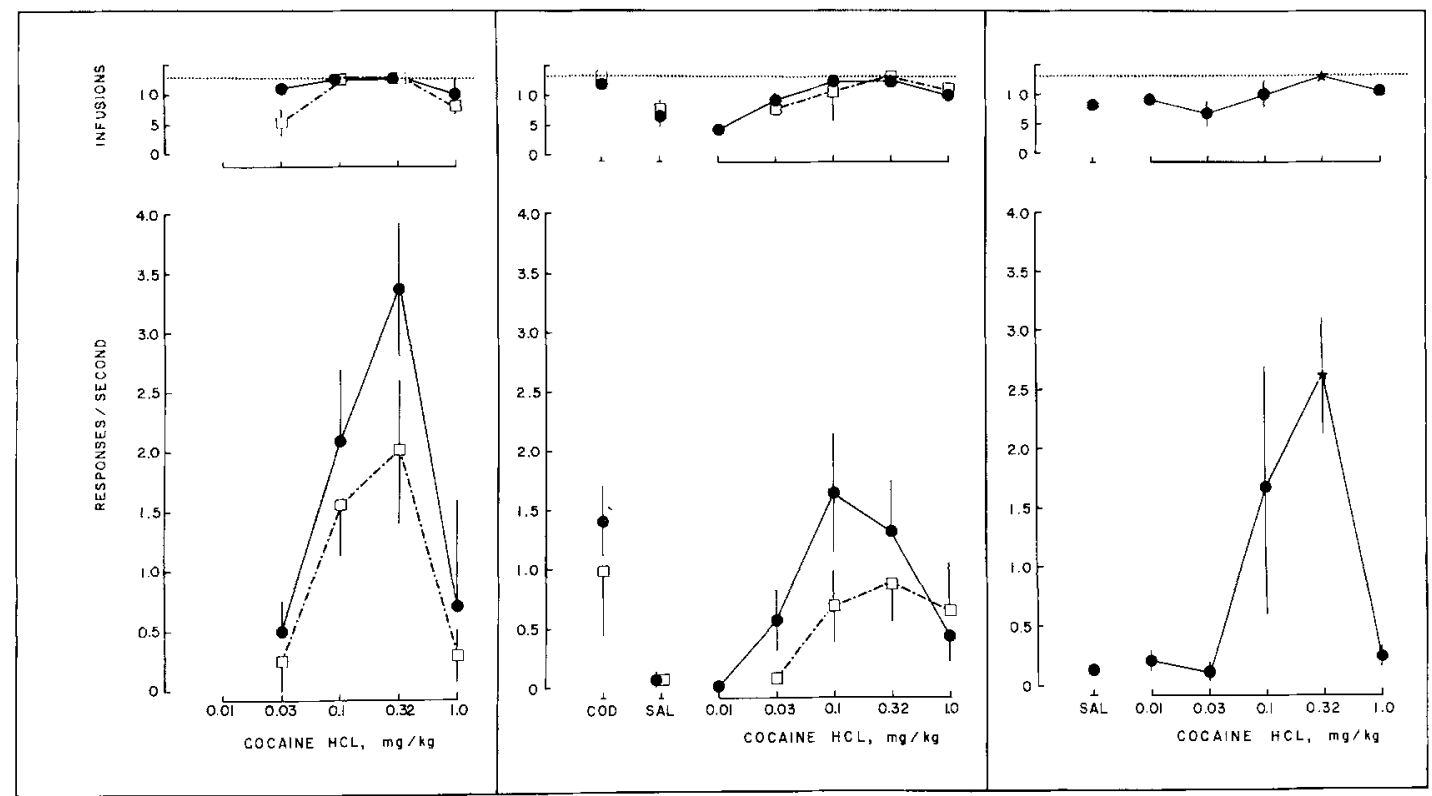

Fig. 4. Response rates and number of injections during the FR component of the FR 30 TO $600 \mathrm{~s}$ schedule of cocaine injection as a function of the cocaine injection dose for two species of macaque. Closed circles and solid lines present data for rhesus macaques; open squares and dashed lines present data for pigtail macaques. The left panel presents data from the final five sessions at each cocaine injection dose under the repeated access procedure; each point represents the mean \pm SEM of individual mean data for four subjects over the five sessions. The middle panel presents data from single substitution sessions in which different cocaine doses were substituted for a $0.32 \mathrm{mg} / \mathrm{kg}$ codeine maintenance dose $(C O D)$. The right panel presents data from single substitution sessions in which different cocaine doses were substituted for a $0.32 \mathrm{mg} / \mathrm{kg}$ cocaine (starred symbol) maintenance dose. For the middle and right panels, each point represents the mean \pm SEM of the average FR response rate of number of injections during two single substitution sessions for each of three rhesus macaques and the mean \pm SEM of single determinations in each of four pigtail macaques. Single session substitutions of cocaine were not studied under the cocaine-maintenance substitution procedure in the pigtail macaque because no veins remained for catheterization. Data from saline substitution sessions are presented at $S A L$. The points at $C O D$ (middle panel) and $0.32 \mathrm{mg} / \mathrm{kg}$ cocaine (right panel) represent the mean \pm SEM of the average data for each subject from two random afternoon maintenance drug sessions during the period of substitution testing. Under all access conditions, the maximum number of injections available per session, indicated by the dotted lines, was 13

frequency of drug injection. For the pigtail macaques, an etorphine injection dose of $0.001 \mathrm{mg} / \mathrm{kg}$ maintained the highest $\mathrm{FR}$ response rates, which also averaged $73 \%$ of the rate maintained by $0.32 \mathrm{mg} / \mathrm{kg}$ codeine. Higher and lower doses maintained FR response rates and injection frequencies that were little higher than those maintained by saline. The FR response rates maintained by $0.32 \mathrm{mg} / \mathrm{kg}$ codeine in these subjects had increased during the period elapsing between tests of different codeine doses and etorphine substitution tests.

Drug Self-Injection: Cocaine. The FR response rates maintained by cocaine were also controlled by the injection dose, the access conditions, and the subject species (Fig. 4). Under the repeated access procedure, FR response rates increased and then decreased as the cocaine injection dose increased (Fig. 4, left panel). At all doses, the pigtail macaques emitted lower FR response rates than did the rhesus. For both species, $0.32 \mathrm{mg} / \mathrm{kg}$ cocaine maintained maximum FR response rates. These rates were higher than the maximum rates maintained by any injection dose of codeine under any access procedure (cf. Fig. 1). At lower and higher injection doses of cocaine, FR response rates and the number of injections received during a session decreased. The frequency of right lever presses during the TO component increased during repeated cocaine access for individual monkeys, but did not vary systematically as a function of injection dose.

The FR response rates maintained by cocaine under the single session substitution procedure were lower when codeine was the maintenance drug than when cocaine was used to maintain responding (Fig. 4, middle and right panels). Under the codeinemaintenance substitution procedure, 0.1 and $0.32 \mathrm{mg} / \mathrm{kg}$ cocaine maintained FR response rates equal to those maintained by the maintenance dose of codeine and lower than those maintained when cocaine was available during consecutive sessions under the repeated access procedure. The pigtail macaques emitted FR response rates roughly equal to those emitted by the rhesus at the higher cocaine doses, but responded at lower rates than the rhesus at the low cocaine doses. Under the cocaine-maintenance substitution procedure, all tested cocaine doses maintained FR response 
rates and total infusions similar to those maintained under the repeated cocaine access procedure for the rhesus monkeys. Comparison of cocaine-maintained response rates under the repeated access and substitution procedures showed that certain doses, $0.32 \mathrm{mg} / \mathrm{kg}$ for the rhesus and 0.1 and $0.32 \mathrm{mg} / \mathrm{kg}$ for the pigtail macaque, maintained higher rates under the repeated access procedure than under the codeinemaintenance substitution procedure, even though the number of cocaine injections delivered at each cocaine dose was equal under the different access conditions. Lower and higher cocaine doses maintained similar FR response rates under all three procedures.

\section{Discussion}

Schedule-controlled behavior of rhesus and pigtail macaques was maintained under a FR 30 TO $600 \mathrm{~s}$ schedule by IV injection of cocaine, codeine, and etorphine. The rate of drug-maintained responding varied as a function of the drug and injection dose, the access conditions, and the species of macaque.

At appropriate doses, cocaine maintained higher response rates during the FR schedule component than did any dose of codeine or etorphine. This difference in the maximum rates maintained by the drugs was not associated with any difference in the frequency of drug injection. At doses of each drug which maintained maximum rates, performance was characteristic of fixed-ratio schedules: when the light associated with the FR component was illuminated, subjects began lever pressing immediately and pressed at a sustained rate until drug delivery. Subjects thus self-injected each drug almost as soon as it was available, and received all available infusions during the experimental session. Previous studies that have directly compared performance maintained by intravenous psychomotor stimulant and narcotic injection in the rhesus monkey under equivalent schedules and access conditions have shown that the psychomotor stimulants maintain maximum rates higher to or equal to those maintained by narcotics. Downs and Woods (1974) reported that cocaine maintained maximum response rates 3.5 times greater than those maintained by codeine under a FR 30 schedule of drug injection without timeout periods separating successive injections. Hoffmeister and colleagues (Goldberg et al. 1971; Hoffmeister and Goldberg 1973), however, reported that cocaine, $d$-amphetamine, and morphine maintained approximately equal maximal rates of lever pressing under FR 10 schedules during three hour experimental sessions.

For cocaine, codeine, and etorphine, FR response rate increased and then decreased as the injection dose increased. This relation between injection dose and response rate is the general rule under simple schedules of reinforcement (e.g. Goldberg, 1976; Pickens et al. 1978). However, both the maximum response rates obtained and the doses of a drug which maintain these rates vary as a function of both the type of schedule and the frequency of drug availability. Under the multiple FR 30 TO $600 \mathrm{~s}$ schedule in the present study, both the maximum rates obtained and the doses of both cocaine and codeine which maintained maximum rates were higher than those reported under FR 10 or FR 30 schedules without accompanying timeout periods in rhesus and squirrel monkeys (e.g., Downs and Woods 1974; Goldberg et al. 1971; Hoffmeister and Schlichting 1972). The higher rates maintained by higher doses of cocaine and codeine in the present study were probably due to the $10 \mathrm{~min}$ timeout period which separated drug availability periods and thereby limited injection frequency. The injection doses of many drugs that maintain maximal response rates are higher under schedules that limit injection frequency than under schedules that allow frequent drug injections, such as small FR schedules (cf. Balster and Schuster 1973; Goldberg and Kelleher 1976; Moreton et al. 1977; Spealman and Kelleher 1979). In general, the drug dose that maintains highest rates under a particular schedule increases as the interinjection interval increases and the frequency of drug injection decreases.

The best-studied schedule that limits injection frequency is the fixed-interval (FI) schedule, under which a drug injection is presented upon the first response which occurs after a fixed time period has elapsed since the previous injection. Although FI schedules control different rates and patterns of responding than do FR schedules (Ferster and Skinner 1957), the relationship between changes in cocaine injection dose and changes in the schedule-controlled response rate appears to be similar for the two schedules when the interinjection times are equal. For cocaine, doses that maintained maximum rates under the FR $30 \mathrm{TO}$ schedule in the present study are similar to those reported by Spealman and Kelleher (1979) to maintain maximum rates under a FI schedule under which injections became available every $10 \mathrm{~min}$. Squirrel monkeys lever pressed under a FI 5-min schedule of cocaine injection that alternated with a FI 5-min schedule of shock presentation or termination. Lever pressing rates increased as the cocaine injection dose increased from 0.01 to 0.1 or $0.3 \mathrm{mg} / \mathrm{kg}$ and then decreased at 0.6 or $1.0 \mathrm{mg} / \mathrm{kg} /$ injection. In the present study, response rates increased as the cocaine injection dose increased from 0.03 to 0.1 or $0.32 \mathrm{mg} / \mathrm{kg}$, then decreased at $1.0 \mathrm{mg} / \mathrm{kg}$. Under interval schedules that specify interinjection intervals longer or shorter than $10 \mathrm{~min}$, higher (Balster and Schuster 1973) or lower (Goldberg 
and Kelleher 1976) cocaine doses maintain maximum lever pressing rates.

This direct relationship between injection frequency and the injection dose that maintains maximum response rates is also apparent for the narcotic codeine. Under FR 10 or FR 30 schedules and variable-interval 2-min schedules, which deliver an injection on the average of once every $2 \mathrm{~min}$, codeine doses of $0.01-$ $0.05 \mathrm{mg} / \mathrm{kg}$ maintain maximum rates (Hoffmeister and Schlichting 1972; Downs and Woods 1974; Carney et al. 1976; Young et al. 1979). In contrast, codeine doses of $0.1-0.32 \mathrm{mg} / \mathrm{kg}$ maintained maximum rates when available at approximately $10 \mathrm{~min}$ intervals in the present study. Increasing the interinjection interval further increases the codeine injection dose that maintains maximal rates. When codeine availability is limited to one injection every $3 \mathrm{~h}$, the highest dose tested, $16 \mathrm{mg} / \mathrm{kg}$, maintains maximal performance under a progressive ratio schedule (Hoffmeister 1979). The effects of injection frequency on response rates maintained by the narcotic etorphine have not been studied.

The access conditions modified the dose-response function for cocaine, but did not markedly do so for codeine. For cocaine, the relationship between injection dose and $\mathrm{FR}$ response rate was identical when cocaine was available during repeated sessions under either the repeated access or the cocaine-maintenance substitution procedure. However, the cocaine injection dose, $0.32 \mathrm{mg} / \mathrm{kg}$, which maintained maximum FR response rates under these access conditions maintained rates almost $50 \%$ lower when codeine was the maintenance drug under the single-session substitution procedure. The lower rates maintained by $0.32 \mathrm{mg} / \mathrm{kg}$ cocaine when codeine was available during the immediately preceding experimental sessions may reflect direct-rate altering actions of this dose under these conditions. Acute exposure to high intravenous cocaine doses decreases rates of schedule-controlled lever pressing maintained by nondrug reinforcers (Balster and Schuster 1973; Johanson 1978 b; Spealman and Kelleher 1979). For example, Spealman and Kelleher (1979) demonstrated that IV administration $0.3 \mathrm{mg} / \mathrm{kg}$ cocaine at $10 \mathrm{~min}$ intervals reliably decreases the frequency of lever pressing maintained by shock presentation in squirrel monkeys. Repeated exposure to cocaine and development of tolerance to such rate disrupting effects (cf. Woolverton et al. 1978) may be necessary in order for high IV injection doses of cocaine to maintain high response rates. The difference in cocaine-maintained performance during sustained exposure to cocaine or codeine may also be the effect of immediate drug-taking history (Schlichting et al. 1971). Schlichting and colleagues reported that $d$-amphetamine was self-injected at higher rates and at higher doses by monkeys self-injecting cocaine during intervening experimental sessions than by monkeys selfadministering codeine during intervening sessions.

Doses of codeine, with one exception, maintained similar FR response rates and similar numbers of injections when studied during consecutive experimental sessions or for single sessions under the codeine- or cocaine-maintenance substitution procedures. In contrast, Hoffmeister and Schlichting (1972) reported differences in codeine-maintained performance between rhesus monkeys exposed to cocaine or codeine. In their study, monkeys were trained to self-inject codeine or cocaine under a FR 10 schedule during daily $3 \mathrm{~h}$ experimental sessions. When different codeine doses replaced the training drug for six successive sessions, the number of codeine injections was higher at injection doses of $0.001-0.5 \mathrm{mg} / \mathrm{kg}$ codeine, as the base, when codeine replaced $0.05 \mathrm{mg} / \mathrm{kg}$ codeine than when it replaced $0.05 \mathrm{mg} / \mathrm{kg}$ cocaine. They also noted that lower injection doses of codeine maintained responding in codeine-experienced animals than in cocaine-experienced animals. In the present study, on the other hand, a codeine dose of $0.1 \mathrm{mg} / \mathrm{kg} /$ injection maintained slightly higher rates, although not an increased frequency of injections, during cocainemaintenance single session substitution tests than when codeine was available during consecutive sessions. The differences in codeine-maintained performance in the two studies may be the result of different subject histories. In Hoffmeister and Schlichting's study, subjects had been exposed only to their particular maintenance drug before the start of substitution testing. In the present study, all monkeys exposed to cocaine maintenance had previously self-injected codeine under the FR 30 TO $600 \mathrm{~s}$ schedule. The similar rates maintained by codeine under both codeine- and cocainemaintenance may have reflected that experimental history.

The pigtail macaque displayed a different pattern of drug self-injection than did the rhesus macaque, and did not appear to be an altogether satisfactory replacement for the rhesus macaque in drug selfadministration studies. The set of pigtail macaques in these experiments did not maintain their catheters as long as an equal number of rhesus macaques studied over the same time period. The pigtail macaques also did not readily acquire codeine-maintained lever pressing. The subset of pigtail macaques that did achieve criterion performance under the FR 30 TO $600 \mathrm{~s}$ schedule of codeine injection displayed lower rates of lever pressing maintained by codeine, etorphine, and cocaine across the range of tested doses under all access conditions than did the rhesus macaques. The two species were similar, however, in the general pattern of drug-maintained performance under both the repeated 
access and the substitution procedures. For both species, FR response rates increased and then decreased as the injection dose of etorphine, codeine, or cocaine increased. In the pigtail macaque, the injection doses of each test drug that maintained maximum $F R$ response rates were equal to or higher than the doses that maintained the higher maximal rates in the rhesus macaque. Cocaine, at appropriate doses, maintained higher $F R$ response rates than did any dose of codeine or etorphine in both macaque species. Thus, those pigtail macaques that maintained intravenous catheters and acquired stable rates of drug-reinforced behavior self-administered the same compounds and displayed the same relationship between injection dose and maximal response rates as did the rhesus macaque.

Acknowledgements. This research was supported by NIDA grant DA-00254. We thank Gail Renard, Janet Fekete, and Wendy Pound for excellent technical assistance and Seymore Herling for helpful comments on the manuscript.

\section{References}

Balster RL, Schuster CR (1973) Fixed-interval schedule of cocaine reinforcement: Effect of dose and infusion duration. J Exp Anal Behav 20:119-129

Carney JM, Llewellyu ME, Woods JH (1976) Variable interval responding maintained by intravenous codeine and ethanol, injections in the rhesus monkey. Pharmacol Biochem Behtav $5: 577-582$

Deneau G, Yanagita T, Seevers MH (1969) Self-administration of psychoactive substances by the monkey. Psychopharmacologia $16: 30-48$

Downs DA, Woods JH (1974) Codeine- and cocaine-reinforced responding in rhesus monkeys: Effects of dose on response rates under a fixed-ratio schedule. J Pharmacol Exp Ther 191:179188

Ferster CB, Skinner BF (1957) Schedules of reinforcement. Appleton-Century-Crofts, New York, p 39

Goldberg SR (1976) The behavioral analysis of drug addiction. In: Glick SD, Goldfarb J (eds) Behavioral pharmacology. C. V. Mosby, Saint Louis, p 283

Goldberg SR, Hoffmeister F, Schlichting UU, Wuttke W (1971) A comparison of pentobarbital and cocaine self-administration in rhesus monkeys: Effects of dose and fixed-ratio parameter. J Pharmacol Exp Ther 171:277-283

Goldberg SR, Kelleher RT (1976) Behavior controlled by scheduled injections of cocaine in squirrel and rhesus monkeys. J Exp Anal Behav 25:93-104
Hoffmeister F (1979) Progressive-ratio performance in the rhesus monkey maintained by opiate infusions. Psychopharmacology 62:181-186

Hoffmeister F, Goldberg SR (1973) A comparison of chlorpromazine, imipramine, morphine and $d$-amphetamine selfadministration in cocaine-dependent thesus monkeys. J Pharmacol Exp Ther 187:8 - 14

Hoffmeister F, Schlichting UU (1972) Reinforcing properties of some opiates and opioids in rhesus monkeys with histories of cocaine and codeine self-administration. Psychopharmacologia 23:5574

Johanson CE (1978a) Drugs as reinforcers. In: Blackman DE, Sanger DJ (eds) Contemporary research in behavioral pharmacology. Plenum, New York, p 325

Johanson CE (1978b) Effects of intravenous cocaine, diethylpropion, $d$-amphetamine and perphenazine on responding maintained by food delivery and shock avoidance in rhesus monkeys. J Pharmacol Exp Ther 204:118-129

Moreton JE, Meisch RA, Stark L, Thompson T (1977) Ketamine self-administration by the rhesus monkey. Pharmacol Exp Ther $203: 303-309$

Pickens R, Meisch RA, Thompson T (1978) Drug selfadministration: An analysis of the reinforcing effects of drugs. In: Iversen LL, Iversen SD, Snyder SH (eds) Handbook of psychopharmacology, vol. 12. Plenum, New York, p 1

Schlichting UU, Goldberg SR, Wuttke W, Hoffmeister F (1971) $d$ Amphetamine self-administration by shesus monkeys with different self-administration histories. In: Proceedings of the Twelfth Meeting of the European Society for the Study of Drug Toxicity, 1970. Excerpta Med. Int. Congr. Ser. 220:62-69

Spealman RD, Kelleher RT (1979) Behavioral effects of selfadministered cocaine: Responding maintained alternately by cocaine and electric shock in squirrel monkeys. J Pharmacol Exp Ther 210:206-214

Wade N (1978) India bans monkey export: U.S. may have breached accord. Science 199:280-281

Woods JH (1978) Behavioral pharmacology of drug selfadministration. In: Lipton MA, DiMascio A, and Killam KF (eds) Psychopharmacology: A generation of progress, Raven Press, New York, p 595

Woods JH (1980) Narcotic-reinforced responding: A rapid evaluation procedure. Drug and Alcohol Dependence 5:223-230

Woolverton WL, Kandel D, Schuster CR (1978) Effects of repeated administration of cocaine on schedule-controlled behavior of rats. Pharmacol Biochem Behav 9:327-337

Young AM, Thompson T, Jensen MA, Muchow LR (1979) Effects of response-contingent clock stimuli on behavior maintained by intravenous codeine in the rhesus monkey. Pharmacol Biochem Behav 11:43-49

Received December 10, 1979; Final version April 18, 1980 